\title{
Artículos
}

\section{Estado, sociedad y economía en El Salvador (1880-1999)}

\author{
Luis Armando González*
}

\begin{abstract}
Resumen
Visión de conjunto de los vínculos fraguados en El Salvador entre la política, la sociedad y la economía desde finales del siglo XIX hasta finales del siglo XX. Para el autor, durante la últimas tres décadas del siglo pasado se echaron las bases del orden económico y social que dominaría a lo largo de casi todo el siglo XX, mientras que, a partir del golpe de Estado del general Hernández Martínez, se inició un esquema de dominación política — cuyo eje central fue el estamento militar - que sólo fue quebrado con los acuerdos de paz de 1992. Una de las principales hipótesis del ensayo es que, en El Salvador de los años noventa, se está operando una reforma estatal la cual se encamina a pasar de un Estado grande, ineficiente e "intervencionista" a un Estado fuerte, eficiente y garante del libre juego de las fuerzas del mercado.
\end{abstract}

\section{Introducción}

Desde el fracaso de la federación Centroamericana (1854) hasta la llegada de Rafael Zaldivar al poder (1876-1884), la vida sociopolítica de El Salvador estuvo marcada por fuertes conflictos -que desembocaban normalmente en enfrentamientos armados- entre "conservadores" y "liberales".

* Director del Centro de Información, Documentación y Apoyo a la Investigación (CIDAI), de la Universidad Centroamericana "José Simeón Cañas".

1. Autores como Adolfo Bonilla han llamado la atención acerca de la utilización del clivaje liberal-conservador como esquema de interpretación de los conflictos en Centroamérica después de la independencia. En concreto, Bonilla apuesta por un clivaje entre constitucionalistas (liberales o republicanos) y absolutistas ilustrados. Ver Bonilla Bonilla, Ideas económicas en la Centroamérica ilustrada 1793-1838, San Salvador, FLACSO, 1999. Para enterarse de múltiples detalles de la vida política centroamericana durante el siglo pasado, ver $\mathrm{A}$. Batres Jáuregui, La América Central ante la historia, 1821-1921. Memorias de un siglo, III Vol., Guatemala, 1949. 
Uno de los ejes de la confrontación era la posición que asumian unos y otros ante la Iglesia y sus privilegios: mientras que los conservadores proclamaban la unidad indisoluble de los intereses de la nación con los intereses clericales, los liberales clamaban por la separación de ambos órdenes e, incluso, por la subordinación del orden religioso al orden civil. Detrás de esa pugna se encontraba una visión distinta de lo que debía ser la organización política de la sociedad y su gestión. Los conservadores apostaban por un ejercicio político fundado en el abolengo y la tradición; la política era patrimonio de aquellos que hereditariamente podían ejercerla. Los liberales anunciaban una nueva forma de hacer política: la gestión política no era asunto de herencia o íradición, sino cuestión de elección por votación popular. Es decir, el pueblo irrumpía con un derecho que le era inalienable: el derecho de elegir a sus gobernantes, los cuales legitimaban su ejercicio en el poder en virtud de este mandato popular, y no en virtud de un designio divino o de sangre.

Ahora bien, si en materia religiosa o en materia política las diferencias entre conservadores y liberales eran tajantes, en el plano económico las tensiones, sin dejar de ser más sutiles, no eran menos graves. El eje de disputa era la tierra, pero la concepción económica era distinta en unos y otros. Para los conservadores, lo importante era la gran propiedad señorial, en cuyos dominios ejercían su poder los grandes terratenientes. La gran propiedad, las caballerizas, el casco de la hacienda, daban la medida del poder de su propietario, siendo secundarias sus actividades productivas. Para los liberales, la tierra importaba en cuanto espacio de producción, en cuanto espacio para generar productos que pudieran ser comerciálizados y que dejaran ingresos a la hacienda pública. Los grandes dominios territoriales improductivos - Orgullo de los conservadores- eran un sin sentido para los liberales, quienes no desaprovecharon las oportunidades para introducir en ellos una dinámica de productividad, lo cual explica la importancia que asignaron varios de sus líderes al café.

Con la muerte de Gerardo Barrios, en $1863^{2}$, el liberalismo más radical cedió su paso a un liberalismo más moderado, al cual le fue fácil convivir con el conservadurismo. Ese acercamiento entre liberales y conservadores tenía dos ejes básicos: (a) la aceptación de que la tierra era la fuente privilegiada para enriquecerse; y $(b)$ que la población indígena-campesina - sobreexplotada y sin derechos de ninguna especie- era la fuente de la mano de obra necesaria para las tareas agrícolas. Sobre estas coincidencias básicas los liberales pudieron convivir con los conservadores, dando lugar a la conformación de los grupos oligárquicos que dominaron la vida económica y política de El Salvador desde las últimas tres décadas del siglo XIX, hasta más allá de la segunda mitad del siglo XX.

De ese modo, en El Salvador, durante la últimas tres décadas del siglo XIX, se echaron las bases del orden económico y social que dominaría a lo largo de casi todo el siglo XX. El ejercicio político caracterizado por la elección de candidatos a la presidencia de entre las familias cafetaleras tuvo vigencia hasta 1931, pues con el golpe de Estado del general Maximiliano Hemández Martínez, en diciembre de 1932 , los militares asumieron la gestión del poder político ${ }^{3}$. Sin embargo, la dinámica de la economía fue regida por los intereses de los cafetaleros hasta bien entrados los años sesenta, cuando, en el marco de una conflictividad sociopolítica sin precedentes en el agro, los sectores industriales y financieros comenzaron a asumir un protagonismo en la conducción de la economía nacional. Recién en las décadas de los años ochenta y noventa, el café perdió su lugar como uno de los ejes fundamentales de la economía salvadoreña ${ }^{4}$.

A la par de un orden económico centrado en la producción-exportación de café, en las últimas tres décadas del siglo XIX se incubó un orden social excluyente y marginalizador de los sectores mayoritarios de la población. La pobreza y el deterioro creciente de las condiciones de vida en el campo fueron los resultados más palpables de la implantación de la lógica cafetalera iniciada por Rafael Zaldívar y continuada por sus sucesores. El descontento y el malestar campesino-indígena fueron contenidos por la violencia estatal, que se convirtió en un componente imprescindible del ejercicio de la autoridad estatal. A la violencia estructural, cuya fuente estaba en la exclusión socioeconómica

2. Ver I. López Vallecillos, Gerardo Barrios y su tiempo, II Vol., San Salvador, Ministerio de Educación, 1965.

3. Ver R. Guidos Véjar, El ascenso del militarismo en El Salvador, San Salvador: UCA Editores, 1980.

4. Ver L.A. González, "El Salvador de 1970 a 1990: política, economía y sociedad”, Realidad, 67, enero-febrero, 1999, pp. 43-61. 
de la mayor parte de la población, se sumó la violencia institucional, componente necesario de un control social siempre huérfano de legitimidad. Éste fue El Salvador que nació a finales del siglo XIX y se consolidó durante las primeras tres décadas del siglo XX. En los años treinta, las familias cafetaleras dejaron la gestión del poder en manos de los militares, quienes se encargaron, durante los siguientes 50 años, de velar porque el orden social y económico surgido en torno a los intereses de las grandes familias cafetaleras perdurara.

\section{Las reformas de Rafael Zaldivar (1876-1884)}

Entre las medidas más importantes tomadas por el gobierno de Zaldívar destacan aquellas orientadas a la confiscación de las tierras ejidales y comunales. En efecto, entre 1879 y 1881 fueron aprobadas una serie de leyes cuyo objetivo inicial era regular el uso de las tierras comunales y ejidales en todo el país; sin embargo, su aplicación llevó a la abolición de todos los sistemas de tenencia comunitaria de la tierra ${ }^{5}$. Las reformas impulsadas por Zaldívar estaban inspiradas en un afán por cambiar lo que el presidente consideraba un sistema arcaico e ineficaz del uso de la tierra: su sueño era ver transformado el campo salvadoreño en un conjunto de propiedades agrícolas que produjeran valiosos frutos, entre los cuales el café ocupaba un lugar de primera importancia.

Los principales beneficiarios de las leyes de abolición de las tierras comunales y ejidales fueron los terratenientes con más dinero. Se valieron de las más diversas artimañas --como la contratación de abogados corruptos y el soborno a alcaldes - para quedarse con las mejores tierras. Por supuesto, las medidas impulsadas por el gobiemo generaron un inmediato malestar social, especialmente en el occidente del país, donde se sucedieron una serie de levantamientos campesinos. En el marco de esas movilizaciones, los rebeldes cortaron las manos a varios jueces repartidores - nombrados por Zaldívar - como castigo por haber repartido tierras que pertenecían a la comunidad. Pese a las protestas, el gobierno llevó adelante su proyecto reformista, amparándose en un sistema de autoridad represivo, dotado de tres elementos básicos: leyes contra la vagancia (para obligar a los campesinos a trabajar en las propiedades cafetaleras), leyes de expulsión de intrusos en las haciendas y creación de una fuerza pública para proteger a los nuevos propietarios agrícolas del saqueo y la venganza. El "Preámbulo del Decreto del 16 de febrero de 1881" dice lo siguiente: "la existencia de tierras bajo propiedad de las comunidades impide el desarrollo agrícola, estorba la circulación de la riqueza y debilita los lazos familiares y la independencia del individuo. Su existencia contraría los principios económicos y sociales que la República ha adoptado" .

La abolición de las tierras comunales y ejidales fue el hecho que dio el impulso definitivo a la expansión de la producción cafetalera en El Salvador. Asimismo, fue a partir de esas transformaciones en la estructura de la tierra que el proceso de constitución de la burguesía cafetalera salvadoreña se volvió irreversible. Y ello porque los esfuerzos de Zaldivar se volcaron hacia el fortalecimiento de las grandes plantaciones de café convertidas en propiedad privada. Tras las reformas de Zaldívar no sólo el café se convirtió en el eje fundamental de la vida económica nacional, sino en el eje del poder político. Los grandes cafetaleros, a la vez que concentraron el poder económico, se aseguraron de que quienes gobernaran lo hicieran —al igual que lo hizo Zaldívar - para ellos. Los gobiemos que siguieron a Rafael Zaldívar hasta el cierre del siglo XIX - Francisco Menéndez (1885-1890), Carlos Ezeta (1890-1894) y Rafael A. Gutiérrez (18951898) - cumplieron este mandato del poder económico, lo cual se continuó hasta las primeras tres décadas del siglo $\mathrm{XX}$, cuando los relevos presidenciales se hicieron constitucionalmente entre miembros de las propias familias cafetaleras.

\section{Las familias cafetaleras en el poder}

Desde una perspectiva política, El Salvador inicia el siglo XX bajo la administración del general Tomás Regalado (1898-1903) ${ }^{7}$. Los antecesores

5. Ver D. Browning, El Salvador, la tierra y el hombre, San Salvador, Ministerio de Educación, 1975, pp. 291 y ss. En adelante seguimos a Browning en su exposición.

6. Acuerdo legislativo, Diario Oficial, 26 de febrero de 1881.

7. Para más detalles sobre los gobiernos salvadoreños del primer cuarto del siglo $\mathrm{XX}$, ver $\mathrm{A}$. Taracena Arriola, "Liberalismo y poder político en Centroamérica (1870-1929)", especialmente los apartados "El Salvador: las 
de Regalado se habían hecho del poder por la fuerza y él continuó esa tradición, pero legitimó su gobiemo a través de unas elecciones que le permitieron ejercer el mando presidencial, sin interrupción alguna, durante cuatro años. Su mayor mérito consistió en lograr, mediante la consolidación de un poder centralizado, un equilibrio político entre los diversos grupos (familias) de la oligarquía. Desde el cierre del siglo XIX, las familias cafetaleras se habían ido perfilando como aquellas con mayor fuerza para hacer que sus intereses se identificaran con los de la nación. Con Regalado se dio un paso importante en esa identificación; empero, fue su sucesor, el finquero Pedro Jesús Escalón (1903-1907), quien se encargó de que la democracia institucionalizada por la Constitución de 1886 - una democracia cafetalera- comenzara a funcionar en la primera década de 1900 . Con Escalón se inició la práctica de que el presidente saliente, teniendo prohibida la reelección, debía elegir a su sucesor para el siguiente período de cuatro años. Además, entre 1907 y 1931 se siguió la regla de elegir presidentes civiles, con la excepción del general Fernando Figueroa (1907-1911).

El juego electoral era claro: las autoridades centrales organizaban las elecciones, ejerciendo un severo control sobre los votantes a través de las autoridades municipales y los finqueros - cafetaleros y cañeros-. Asimismo, se trataba de controlar al máximo la postulación de candidatos opositores. La votación no era secreta y duraba tres días seguidos; ello hacía indispensable el control de las muncipalidades, pero también hacía necesaria la colaboración del ejército -el mejor equipado, entrenado y pagado de Centroamérica-, que veía en su alianza con la élite cafetalera una oportunidad para promover sus intereses corporativos. En 1911 llegó al poder Manuel Enrique Araujo (19111913), quien buscó dotar a su gobierno de una mayor autonomía respecto de los intereses de los terratenientes, lo cual lo acercó a los intereses de los exportadores que eran sujetos de crédito por parte de inversionistas extranjeros. Araujo también buscó acercarse a otros sectores sociales, como los artesanos -creando sociedades artesanales-, y a los líderes opositores - a través del llamado "transformismo"- Entre tanto, su política hacia el sector indígena estuvo orientada a forzarlos a que se ajustaran a una economía monetaria y a que asumieran un estilo de vida ladino.

Para Araujo, los militares continuaron siendo unos aliados imprescindibles. De hecho, su gobierno reforzó lazos con el estamento castrense, estableciendo el servicio militar obligatorio, mejorando los servicios de la Escuela Militar y creando la Guardia Nacional (GN), para lo cual nombró al general José María Peralta Lagos, reconocido intelectual, como Ministro de Guerra. Araujo fue asesinado, en una situación confusa, en 1913, en un momento en que los inversionistas ingleses se batían en retirada de Centroamérica y la diplomacia del dólar — a la que Araujo se resistía- se inauguraba en la región. Luego del asesinato de Araujo, para reemplazarlo, llegó al poder el vicepresidente Carlos Meléndez (1913-1918), quien finalizó el mandato del presidente fallecido y luego, al ganar las elecciones de 1915, asumió constitucionalmente la presidencia. Con la llegada al poder de Carlos Meléndez se inició la "dinastía" de los Meléndez-Quiñónez, que se caracterizó por aglutinar a quienes, desde la producción y exportación de café, concentraron enormes cantidades de dinero. Las familias, que se contaban entre las más importantes en la producción y exportación del grano, lograron monopolizar el poder político. Meléndez, al contrario que su antecesor, facilitó la penetración de capital estadounidense en el territorio nacional, en un momento en que las inversiones inglesas iban en declive.

Jorge Meléndez reemplazó a su hermano en 1919. El segundo de los Meléndez en el poder

desigualdades crecientes y el orden liberal" y "El Salvador: la frustración del intento de democratización". En V.H. Acuña Ortega (Editor), Historia general de Centroamérica. Las repúblicas agroexportadoras, San José: FLACSO, Costa Rica, 1994, pp. 167-250. 
hizo que su grupo familiar, sus amigos y socios expandieran sus operaciones hacia el comercio y la agricultura, al amparo de las inversiones estadounidenses. Paralelamente a este aumento desmesurado de la riqueza en unas pocas manos, se suscitó un agudo contraste con la forma de vida de la mayor parte de la población, lo cual fue inseparable de una inevitable contestación política, especialmente en San Salvador, a donde habían comenzado a emigrar cientos de campesinos sin propiedad.

El fuerte desequilibrio social cobró visos de protesta política, ante la cual el gobiemo organizó la "Liga Roja", que tenía por objeto, mediante la violencia paramilitar, amedrentrar a los opositores políticos. El desgaste de Jorge Meléndez fue evidente; incluso se vio obligado a imponer un "Estado de sitio" para enfrentar las críticas y protestas sociales y políticas. Pese a ello, la lógica dinástica continuó y para las elecciones de 1923 fue designado como candidato su cuñado Alfonso Quiñónez Molina (1923-1927), quien gobernó durante los años de mayor auge cafetalero. Quiñónez Molina, aunque pretendió recuperar el proyecto liberal, se entrampó en las redes impuestas por los intereses vinculados al café. De aquí que su gobierno se caracterizara por propiciar una cierta apertura sociopolítica vinculada a recurrentes medidas de coacción estatal en contra de los anarquistas, comunistas y laboristas que, aunque minoritarios, proclamaban ideas incendiarias - sobre todo, los dos primeros- que hacían temer lo peor a la clase política reinante y a los terratenientes. No obstante, Quiñónez Molina disolvió la "Liga Roja" y, desde 1924, propició el reconocimiento legal a los sindicatos. Además fue partidario de un cierto "intervencionismo" estatal en la diversificación de cultivos, el sistema de ahorros y las compañías aseguradoras.

Quiñónez Molina fue sucedido en el poder por Pío Romero Bosque (1927-1931). Éste se preocupó por buscar un respaldo social en las clases mayoritarias. Pese a estar vinculado a los intereses cafetaleros, Romero Bosque intentó democratizar el sistema político, para lo cual suprimió el "Estado de sitio", creó el Ministerio de Trabajo y sentó las bases para la creación de una legislación de las relaciones obrero-patronales. Por supuesto, ello tenía sus límites y éstos eran que el movimiento sindical no afectara los intereses de los cafetaleros.
La apertura de Romero Bosque rindió sus frutos en la creación de una serie de partidos políticos independientes, así como a la generación de una prensa que difundió ampliamente ideas nacionalistas -que atacaban a las compañías extranjeras y a Estados Unidos - y democráticas - a favor de la tolerancia y el pluralismo-. Fue este intento de democratización del sistema político y de la sociedad lo que quiso continuar el sucesor de Romero Bosque, Arturo Araujo. Éste último, con su Partido Laborista - formado según el modelo inglés-, pretendió ser el benefactor de la clase obrera, por lo cual pronto se afiliaron al mismo trabajadores urbanos y campesinos, quienes fueron fuertemente influenciados por el proselitismo y las ideas de Alberto Masferrer. El 22 de enero de 1931 se realizaron las elecciones presidenciales con los resultados siguientes: Araujo (Partido Laborista en coalición con la Unión Vitalista): 104083 votos; Alberto Gómez Zárate (Partido Zaratista): 64 259; Enrique Córdova (Partido Evolución Nacional): 34 219; Miguel Tomás Molina (Partido Constitucional): 4 911. Ninguno de los candidatos obtuvo mayoría absoluta, por lo que la Asamblea Legislativa tuvo que decidir quién iba a ser el nuevo presidente ${ }^{8}$.

La elección recayó en Araujo, quien tomó posesión el 1 de marzo de 1931, estando en pleno auge los efectos de la crisis mundial de 1929-30. La manifestaciones contra el gobierno se pusieron a la orden del día, sin que éste pudiera responder adecuadamente ante la situación. La agitación social y el malestar de los grupos de poder económico eran extremos, y el 2 de diciembre Araujo fue derrocado por un golpe de Estado que llevó al poder al general Maximilano Hernández Martínez, hasta ese momento vicepresidente de la república. Con el arribo de Hernández Martínez se inició un proceso de recomposión del ejercicio del poder político en el país, cuyo preámbulo fue la crisis política de 1932.

\section{La crisis de 1932, la dictadura martinista y el Estado militar}

El Partido Comunista de El Salvador (PCS), la organización política más beligerante a principios de los años treinta y durante la revuelta campesina, fue desarticulado en 1932, justo dos años después de haber sido fundado. Esta desarticulación se produjo en el contexto de la crisis de 1929 que afec-

8. Para un examen de la coyuntura electoral de 1931, ver R. Guidos Véjar, op. cit, pp. 104 y ss. 
tó en forma grave a El Salvador. Los precios del café - principal sostén de la economía nacional- bajaron en forma estrepitosa. Las haciendas cafetaleras más importantes disminuyeron bruscamente sus niveles de producción, lo cual generó un desempleo masivo en el campo y agudizó la miseria de amplios sectores de la población campesina, que dependían casi exclusivamente del empleo temporal que les ofrecía la corta de café una vez por año".

En San Salvador, las nacientes clases medias -compuestas básicamente por empleados estatales y militares - vieron disminuidos en forma sustancial sus ingresos, ya que las arcas fiscales se vaciaron como resultado de la crisis que abatía al agro. En general, en el país se vivía un clima de agitación social, cuyo epicentro se ubicaba en la zona occidental del país, donde se encontraban concentradas las principales haciendas cafetaleras. En El Salvador se conjugaron, en esta coyuntura, el deterioro de la situación económica y las protestas sociales, especialmente campesinas. El colapso de Wall Street ocasionó una drástica baja en los precios del café y en los salarios de los trabajadores de las fincas que lo producían. En 1931, el precio de exportación descendió hasta 18 colones cada quintal de café $(1$ quintal $=100$ libras $=46$ kilogramos), cuando en 1927 el costo había sido de 32 colones y en 1928, de 39; los salarios bajaron hasta 20 centavos por día en 1930 , lo cual era mucho menos de la mitad pagada antes de la crisis de la bolsa de valores. No es sorprendente, por tanto, que los revolucionarios fuesen capaces de organizar a unos 80000 trabajadores agrícolas - principalmente peones de las fincas de café al oeste de El Salvador - en sindicatos militantes. Hubo huelgas y, en mayo de 1930, se organizó una manifestación masiva en San Salvador.

En el marco de esta conflictividad socioeconómica se produjo el golpe de Estado del general Maximiliano Hernández Martínez, en diciembre de 1931, al gobiemo de Arturo Araujo, quien un año antes había asumido la presidencia de la República. Hernández Martínez fue apoyado por una fracción importante de la oligarquía cafetalera inconforme con' la incapacidad de Araujo para enfrentar la situación. En enero de 1932, el nuevo gobierno convocó a unas elecciones en las cuales participó el Partido Comunista Salvadoreño, que en forma creciente - durante las votaciones- hizo sentir su fuerza electoral en diferentes lugares del país.

El general Hemández Martínez suspendió el proceso electoral y, pocos días después ( 7 u 8 de enero), el Partido Comunista Salvadoreño hizo un llamado a la insurrección. El 22 de enero se produjo un levantamiento campesino en la zona occidental del país. Según algunos autores, se trató de un levantamiento espontáneo e indetenible. Y, aunque la insurrección fue sofocada, la Guardia Nacional y la propia burguesía agraria, mediante la organización de las llamadas "guardias cívicas", procedieron a asesinar en masa a la población trabajadora del campo, en particular a la población de origen indígena, lo cual hizo que el control de la rebelión cobrara un fuerte carácter de etnocidio. Aunque no hay datos exactos en torno al número de muertos como resultado de las acciones punitivas emprendidas por el gobierno de Martínez, los cálculos oscilan entre los 20 y 30 mil asesinados ${ }^{10}$.

Durante el período en que Hernández Martínez estuvo en el poder ${ }^{11}$ fueron fuertemente violentadas las libertades constitucionales de los salvadoreños, en especial las de aquellos que contaban con los medios para hacer algún tipo de oposición. La prensa nacional - tanto la que seguía una orientación en favor de las libertades cívicas como la que promovía una oposición al régimen, en virtud de las medidas económicas que decidió tomar en contra de las familias más ricas del país-- fue sometida a una constante censura y la Universidad de El Salvador prácticamente perdió su autonomía. Los únicos que estuvieron fuera del alcance del dictador fueron los propios militares cuya pro-

9. Ver Salazar Valiente, M., "Crisis, dictadura, lucha (1920-1980)". En P. González Casanova (Coord.), América Latina: historia de medio siglo, 2. Centroamérica, México y El Caribe, México: Siglo XXI, 1993, pp. 87-122.

10. Para algunos autores, como A. White, murieron entre 15 y 20 mil personas. Ver A. White, El Salvador, San Salvador: UCA Editores, 1996, pp. 122. Para el examen de las dimensiones del levantamiento campesino y el nivel de represión estatal, ver Th. Anderson, El Salvador, 1932 (Los sucesos políticos), San José: Educa, Costa Rica, 1976.

11. Para un examen de conjunto de la dictadura de Hernández Martínez, ver V. Búlmer Thomas, "La crisis de la economía de agroexportación (1930-1945)", específicamente el apartado "La consolidación de la dictadura". En V.H. Acuña Ortega, Historia general de Centroamérica. Las repúblicas agroexportadoras, San José: FLACSO, Costa Rica, 1994, pp. 325-399. 
fesionalización era una de las metas de Hemández Martínez-, que en forma constante fraguaron conspiraciones y lanzaron fuertes críticas a algunas de las decisiones tomadas por éste, en especial a la que condujo a la creación de milicias armadas entre sus partidarios.

Paralelamente a estas medidas dictatoriales, el gobierno hizo todo cuanto pudo por sacar a la producción cafetalera del estancamiento, para lo cual desempeñó una importante función el Banco Hipotecario (estatal) creado para ayudar a los cafetaleros. A ello se sumaron sus esfuerzos por lograr la estabilidad monetaria al centralizar la emisión de la moneda en el Banco

Central de Reserva (BCR). Asimismo, el gobierno mostró una cierta preocupación por el fomento del desarrollo manufacturero, como lo muestra el establecimiento de una fábrica, con concesión de monopolio, para producir localmente bolsas para el comercio de café, antes importadas, hechas de henequén cultivado en el país. Asimismo, a fines de los años 30, tres hilanderías producían textiles de algodón.

El general Hernández Martínez fue derrocado en $1944^{12}$, siendo propiciada su caída, a nivel internacional, por el movimiento antifascista que se propagó en Europa y América ante el derrumbe inminente del nacional socialismo alemán y del fascismo italiano, así como por los movimientos democráticos que, desde el interior de El Salvador, aprovecharon la coyuntura antifascista para exigir la instauración de un régimen político constitucional. En este clima se forjó una alianza entre una fracción de la oligarquía - molesta por algunas de las medidas tributarias de Hernández Martínez que afectaban sus intereses, los cuales encontraron eco en El Diario de Hoy-, representantes de los grupos medios y populares, y militares jóvenes del ejército con el propósito de derrocar a la dictadura mediante un golpe de Estado cívico-militar. El dos de abril de 1944 se produjo una sublevación que fue controlada por Hernández Martínez y a la que le siguió el fusilamiento de sus principales dirigentes. La revuelta tomó la forma de un golpe militar que fracasó, pero San Salvador tomó la forma de un campo de batalla durante dos días, resultando muchos heridos y muertos.

Ante estas arbitrariedades del dictador, la sociedad civil respondió con la llamada "huelga de brazos caídos" que, liderada por grupos estudiantiles, paralizó casi totalmente la vida nacional. El golpe final ocurrió el 7 de mayo, cuando un estudiante, José Wright, miembro de la élite salvadoreña, fue asesinado a tiros por un policía. Al día siguiente, el embajador de Estados Unidos aconsejó a Martínez renunciar y éste acató la recomendación.

Las protestas que forzaron la salida de Hernández Martínez no sólo dieron un nuevo aliento al proceso de organización de los trabajadores, suspendido violentamente en 1932, sino que inauguraron la irrupción de las clases medias - estudiantes, maestros y empleados- como agentes dinamizadores de la vida política nacional. Desde los preparativos de la "huelga de brazos caídos" hasta su culminación, la función de los sectores medios fue decisiva. Desde entonces, las clases medias han estado presentes, como protagonistas, en las principales etapas del proceso sociopolítico salvadoreño a lo largo del siglo XX. Junto a ellas, los "militares jóvenes" van a representar, a partir de 1931, una orientación en las filas del ejército, en oposición a la línea dura y proclive de la exclusión, defensora de la institucionalidad del país y de las reformas necesarias para reducir los niveles de pobreza. Esas dos orientaciones en las filas del estamento militar son las que convivieron, pactando y haciéndose concesiones mutuas, desde que los militares iniciaron su gestión del aparato estatal en 1931. Así, pese a que Hernández Martínez se vio forzado a abandonar el país, después de él -y sin interrupción hasta 1979- los militares no

12. Sobre la caída de Hernández Martínez, ver M. Rojas Bolaños, "La política", especialmente el apartado "El Salvador: el golpe de los mayores". En V.H. Acuña Ortega, Historia general de Centroamérica. De la postguerra a la crisis, San José: FLACSO, Costa Rica, pp. 85-165. 
sólo decidieron el rumbo político de El Salvador, sino que en buena medida también - a veces en connivencia con y a veces en contra de los grupos de poder económico- decidieron el modelo de desarrollo que consideraron adecuado para el país.

En efecto, con la salida del dictador, El Salvador comenzó lo que parecía ser una nueva etapa en su vida política: la fase - atravesada por continuos golpes de Estado- de la lucha partidaria por la gestión del Estado. Esta fase coincidió con los inicios del protagonismo económico de la burguesía industrial, el cual se frustró en forma dramática con el fracaso del proyecto sustitutivo de importaciones plasmado en el Mercado Común Centroamericano (MERCOMUN), mismo que se quebró definitivamente cuando estalló la guerra entre El Salvador y Honduras en $1969^{13}$. El movimiento popular - actor fundamental en el triunfo de la huelga de brazos caídos- se aglutinó en torno a la figura del líder populista Arturo Romero y el Partido Unión Democrática (PUD) - del que Romero era el líder-y se preparó para el proceso electoral convocado por la Junta de Gobiemo, formada tras la renuncia de Hernández Martínez, mientras que la oligarquía y los grupos sociales más conservadores se agruparon en torno al Partido Agrario (PA). El Partido Comunista de El Salvador (PCS), principal fuerza política durante el levantamiento campesino de 1932 , no tenía mucho que ofrecer en estas circunstancias dada su debilidad organizativa y la escasa base social con la que contaba $^{14}$.

Tras una larga etapa de golpes de Estado y elecciones - toda ella girando en tomo al estamento militar--, el golpe de Estado de 1979 fue el último de la larga cadena que se inició en 1931. La coyuntura que se abrió después de octubre de $1979^{15}$ fue cualitativamente distinta a las vividas con anterioridad. En 1979 se cerró una fase de la historia política de El Salvador y se abrió otra, la cual estuvo marcada por la emergencia del Frente Farabundo Martí para la Liberación Nacional (FMLN), como princi- pal polo de oposición frente al Estado, y por el estallido de una guerra civil en la que justamente se confrontaron el proyecto insurgente y el proyecto gubernamental. En todo el período histórico dominado por ellos, los militares intentaron impulsar un nuevo modelo de dominación política y económica centrado en una serie de reformas socioeconómicas, la modernización estatal y la coacción.

Sin embargo, ese modelo adolecía de una debilidad fundamental ${ }^{16}$, ya que se apoyaba en la creencia de que el café tenía una importancia primordial y que debía evitarse que la operación de ese sector se viera afectada por reformas que pudieran alterar el precario equilibrio de un país con muy poco territorio, una economía emergente y una población que crecía con gran rapidez. Los militares no pudieron caer en la cuenta de que la operación del sector cafetalero no estaba indisolublemente ligada a la oligarquía por una especie de hechizo histórico irrompible.

Desde su arribo al poder estatal hasta 1979 , los militares fueron incapaces de tomar conciencia sobre las necesidades sociales, políticas y económicas del país y de que éstas, a su vez, exigían no sólo reformas estructurales, sino también una apertura política que sólo podía hacerse efectiva con el apoyo del estamento militar. No valoraron adecuadamente el poder político y económico de los grupos productores-exportadores de café, a partir del cual éstos podían impedir cualquier tipo de reforma. Como dice Baloyra: "Los militares pudieron haber jugado un papel crucial en este proceso, tal y como lo hicieron en otros países de América Latina, pero en El Salvador no lo hicieron. En cambio, durante las tres décadas siguientes, controlaron la sociedad sin llegar a dominarla. No lograron convertirse en el actor hegemónico que podría reemplazar a la oligarquía; perdieron varias oportunidades de formar coaliciones importantes e impidieron el que otros las formaran"17.

La pretensión de los militares de propiciar una cierta industrialización, así como una legislación

13. Ver "El conflicto Honduras-El Salvador", ECA, 254-255, noviembre-diciembre, 1969 (número monográfico).

14. Ver M. Salazar Valiente, "Crisis, dictadura, lucha... (1920-1980)". En González Casanova (Coord.), América Latina: historia de medio siglo. 2. Centroamérica, México y El Caribe, México: Siglo XXI, 1993, pp. 87-122.

15. Para detalles sobre el golpe de Estado, ver T. Guerra, El Salvador: octubre sangriento. Itinerario y análisis del golpe militar del 15 de octubre de 1979, San José, Centro Víctor Sanabria, 1979.

16. En esta argumentación seguimos a Enrique Baloyra, El Salvador en transición, San Salvador: UCA Editores, 1984, pp. 35-36.

17. Ibid., p. 36. 
que protegiera mínimamente los derechos de los trabajadores —el reformismo militar- dejó intacta la sociedad salvadoreña. "Los cambios ocurridos -insiste Baloyra - no fueron planeados y, en la mayoría de los casos, ni siquiera previstos. Los gobiemos militares no fueron oligárquicos, pero sí beneficiaban a la oligarquía; todos esos gobiemos fueron dictaduras militares; no se permitió nunca que las instituciones republicanas prosperaran ni siquiera que operaran por algún período considerable"18. La presencia de los militares, pues, terminó siendo decisiva en el país, con su subsiguiente militarización. De aquí que una de las vertientes de las reivindicaciones populares y de los sectores medios se orientó a clamar por el fin del militarismo, lo cual no sólo fomentó el espíritu de cuerpo del estamento militar, sino que también contribuyó a que la distancia que los militares habían establecido con la sociedad se volviera más abismal. Una importante dosis de resistencia civil y popular al militarismo fue la que alimentó al movimiento insurgente durante los años ochenta y principios de los noventa. Los acuerdos de paz dieron cabida a ese clamor, al plantarse como uno de sus principales objetivos la salida de los militares del ejercicio directo del poder político.

\section{La recomposición del Estado (1980-1994)}

Como hemos visto, el año 1931 constituye un parteaguas en la historia salvadoreña. A partir de ese año el estamento militar asume el control y la gestión del aparato estatal, con lo que se produce lo que se ha dado en llamar el "ascenso del militarismo" en El Salvador (Guidos Véjar, 1980). Hasta ese entonces, la gestión estatal había sido llevada adelante directamente por miembros de la oligarquía o por miembros de la clase política allegados a los grupos dominantes que, a través de un incipiente mecanismo de participación electoral, garantizaban no sólo su continuidad en el poder sino la identificación de los intereses del Estado con los intereses de los grupos oligárquicos vinculados a la producción y exportación cafetalera, y el compromiso del mismo con la reproducción de un modelo económico anclado en la agroexportación. La crisis de $1929-y$ sus repercusiones en la estruc- tura socioeconómica del país - se tradujo en una severa crisis política que hizo inviable la continuidad de la gestión oligárquica del aparato estatal. La incapacidad política de la oligarquía para hacer frente a la conflictividad social generada por la crisis, particularmente el levantamiento campesino de 1932, trajo consigo un vacío de poder que fue ocupado por el estamento militar.

Desde 1931 hasta octubre de $1979-$ con breves interludios que llevaron al poder, por la vía de los golpes de Estado, a una serie de juntas cívico militares o juntas de gobiemo-, los militares gobernaron el país, en estrecha alianza con los grupos oligárquicos, pero con la suficiente autonomía como para intentar, al menos, impulsar políticas económicas y sociales no del todo acordes con los intereses inmediatos de los grupos de poder. Los grupos dominantes, por su parte, se desvincularon de la actividad específicamente política y centraron su quehacer en el ámbito económico.

Sin embargo, irrumpieron con virulencia en la vida política del país cuando desde el Estado emanaron iniciativas contrarias, al menos en el corto plazo, a sus intereses. Éste fue el caso, por ejemplo, del proyecto de transformación agraria impulsado por el gobiemo del coronel Arturo Armando Molina, entre 1975 y 1976, que desató la ira de la derecha económica y la obligó a lanzar, a través del Frente de Agricultores para la Región Oriental (FARO) y de la Asociación Nacional de la Empresa Privada (ANEP), una campaña sistemática de ataques contra el gobiemo y contra aquellos sectores de la sociedad que respaldaban el proyecto de la reforma del agro. Como resultado de la ofensiva del gran capital, el gobierno retrocedió y el intento reformista fue abortado ${ }^{14}$. Ahora bien, esta irrupción de los grupos dominantes en la vida política tuvo más un carácter gremial que un carácter específicamente político, sobre todo por la índole de la organización que articuló y encauzó los intereses del gran capital. Más aún, una vez que la batalla fue ganada, los militares continuaron con la gestión del aparato estatal, gozando de la relativa autonomía con la que hasta entonces habían estado operando, mientras que los grupos de poder económico volvieron a sus negocios privados.

18. Ibid.

19. Ver L.A. González, L.E. Romano, “El cooperativismo en El Salvador (1970-1990)”, Realidad, 68, pp. $175-206$. 
Para que la derecha económica irrumpa de un modo estrictamente político - y organizada políticamente- habrá que esperar hasta principios de la década de los ochenta, cuando es fundado el partido ARENA. A partir de este momento, la derecha inicia un proceso de reacomodo y organización política con miras a acceder a la gestión estatal ${ }^{20}$; este acceso se comienza a gestar en las elecciones para la Asamblea Constituyente, en 1982, y se hace efectivo en los procesos electorales de 1988 , 1989 y 1994, a partir de los cuales se concreta el retorno de los grupos de poder económico al ejercicio político a través de la presencia de varios de sus miembros en el partido ARENA. Durante la administración de Armando Calderón Sol (19941999), la derecha económica, específicamente el sector dedicado a la actividad financiera, no sólo consolida su proyecto político-económico, sino que lo convierte en el proyecto hegemónico.

Para comprender el significado del retorno de los grupos de poder económico al poder estatal, es conveniente volver sobre el proceso sociopolítico iniciado el 15 de octubre de 1979. En efecto, el golpe de Estado de octubre de 1979 desencadenó un proceso de transformación en los mecanismos de gestión del aparato estatal. A partir del 15 de octubre de 1979, los militares abandonan la gestión del Estado, con lo cual dejan un espacio de poder que requiere de una élite dirigente capaz de relanzar el modelo de dominación establecido o de diseñar otro nuevo. En este contexto emergen los tres proyectos sociopolíticos que se van a disputar el poder a lo largo de la década de los ochenta: el proyecto contrainsurgente (Fuerza Armada, Partido Demócrata Cristiano y gobierno de Estados Unidos), el proyecto insurgente (FDR-FMLN) y el proyecto de la derecha (ARENA, FUSADES y ANEP) ${ }^{21}$.

Los proyectos insurgente y contrainsurgente constituyeron los polos principales de la dinámica sociopolítica del país prácticamente hasta finales de la década de los ochenta. Sin embargo, a raíz de los procesos electorales de 1988 y 1989 , se produce una modificación sensible a nivel de las élites que conducen políticamente a la nación: en 1988, el partido ARENA se queda con la mayoría de los escaños en la Asamblea Legislativa; mientras que, en 1989, desplaza del ejecutivo a la democracia cristiana, lo cual hace colapsar el proyecto contrainsurgente que contaba con los demócrata cristianos como uno de sus ejes de apoyo. Como resultado de ello, desde finales de la década hasta la firma de los acuerdos de paz (1992), los polos de la confrontación sociopolítica estuvieron constituidos por el proyecto de la derecha, liderado por ARENA, y el proyecto insurgente. La derecha terminó por convertirse en el interlocutor político del proyecto abanderado por el FMLN-FDR.

Durante la década de los años ochenta, ARENA diseñó los mecanismos organizativos necesarios para hacerse de la gestión estatal a través de la vía electoral. La estrategia de ARENA cosechó sus frutos en 1988 y 1989. Así pudo llevar adelante, desde el gobierno y con el respaldo decidido de importantes sectores empresariales, el proceso de negociación con el FMLN, con el cual se puso término en forma definitiva a doce años de guerra civil. En las elecciones de 1994, ARENA consolida su hegemonía política ${ }^{22}$, lo cual le permite apuntalar el proyecto socioeconómico iniciado en 1989. ¿De qué proyecto se trata? ¿Cuáles son sus líneas maestras tanto en materia de política económica como en materia de política social?

\subsection{Las dos administraciones de ARENA (1989-1999)}

A partir de la década de 1980, el quiebre de la agricultura como eje principal de la economía nacional ha traído aparejado el fortalecimiento del comercio y las finanzas, a un grado tal que, desde finales de la década pasada, se inició un proceso de "terciarización" de la economía nacional; es decir, ha conducido a un proceso en el cual el sector terciario se ha convertido en el mayor movilizador de capitales, con el subsecuente desarrollo de la infraestructura asociada al sector -imponentes centros financieros y grandes complejos comerciales-. El crecimiento del sector terciario no ha

20. Ver G.G. Tapia, La transición en América Latina.' Los casos de Chile y El Salvador, San Salvador, CINAS-AMIztapalapa, 1991, pp. 83 y ss.

21. Ver G.G. Tapia, El Salvador. ¿Empate militar o multiplicidad de conflictos?, México, 1987.

22. Ver C. Acevedo, "Las elecciones generales de 1994: consolidación de la hegemonía de ARENA", ECA, 545 546, marzo-abril, 1994, pp. 195-212. 
sido ajeno a los reacomodos experimentados por el Estado salvadoreño, no sólo en su estructura interna - modernización estatal-, sino en su relación con la economía -reprivatización de los bienes estatizados por las juntas de gobiemo en la década de los ochenta y privatización de servicios que desde su creación fueron servidos por el Estado, como la energía eléctrica y las pensiones de retiro-. Primero la administración del ex presidente Alfredo Cristiani y, después, la del presidente Armando Calderón Sol han contribuido decisivamente a afianzar el giro hacia la terciarización de la economía nacional, al asumir, cada una con matices y énfasis distintos, elementos del programa de reformas neoliberales - como la apertura externa, la reducción del Estado y la privatización de servicios públicos-, orientando los beneficios de esas reformas hacia el sector financiero ${ }^{23}$.

En el marco de esos propósitos ambas administraciones han impulsado una reforma del Estado con miras no sólo a hacerlo más eficiente -mediante su modemización-, sino a reducir sus presencia en la economía. Este segundo objetivo ha sido logrado, primero, reprivatizando los recursos que fueron expropiados por las juntas revolucionarias de gobierno de los años ochenta: la banca y el comercio exterior. En segundo lugar, ambas administraciones han promovido la privatización de servicios, como las telecomunicaciones y las pensiones de retiro, que desde su creación estuvieron en manos del Estado. De este modo, de un Estado grande, ineficiente e "intervencionista" se pretende pasar a un Estado fuerte, eficiente y garante del libre juego de las fuerzas del mercado. La reforma estatal todavía está en marcha, por lo que es imposible hacer evaluaciones definitivas sobre su éxito o fracaso, o acerca de hacia dónde nos llevará.

\subsubsection{La administración Cristiani (1989-1994)}

\section{A. Políticas económicas}

El marco englobante de las políticas económicas, bajo la administración Cristiani, es el esfuerzo por reorientar la economía con el objeto de "establecer un sistema de economía social de mercado, ya que ésta ofrece las mejores expectativas para alcanzar los objetivos globales del Plan de Desarrollo Económico y Social: obtener un crecimiento robusto y sostenido en el tiempo y elevar las condiciones de vida de toda la población, con énfasis en los grupos desposeídos"24. Tal como se formulan en el Plan de desarrollo económico y social 1989-1994, lo que se busca es implementar un modelo de desarrollo económico que contribuya a: (i) crear las condiciones para la erradicación paulatina de la extrema pobreza; (ii) lograr que el crecimiento económico sea sostenido en el tiempo; (iii) reducir el rol protagónico del estado, y (iv) estimular el pleno y eficiente uso de los recursos del país ${ }^{25}$.

En función de los anteriores propósitos se plantea una estrategia económica "orientada a superar la crisis en el corto plazo, de sanear y reformar las estructuras económicas en el mediano plazo, para fortalecer los mecanismos de mercado y generar las condiciones mínimas y necesarias para el funcionamiento eficiente de la economía. Las líneas de estrategia procuran remover los obstáculos que entorpecen el desarrollo sostenido y generalizado, a la vez de generar los mecanismos indispensables para el funcionamiento fluido y eficiente de la economía". Esa estrategia contempla las siguientes líneas de acción: (i) "un programa de estabilización, el que comprende el período junio de 1989 a diciembre de 1990"; y (ii) "una reorientación de la economía a través de una readecuación integral de las estructuras, y el fortalecimiento de los mecanismos que alimenten el potencial competitivo e innovador de las fuerzas económi$\operatorname{cas}^{226}$.

Las grandes metas por lograr a partir de esa estrategia son las siguientes:

(i) Modernización institucional. "La estructura administrativa del Gobierno de El Salvador tiene una concepción de amplia participación del Estado en las actividades de la sociedad salvadoreña.

23. Ver CIDAI, "El Salvador en 1997: política, economía y sociedad", ECA, 591-592, enero-febrero, 1998, pp. 1742.

24. Ministerio de Planificación y Coordinación del Desarrollo Económico y Social (MIPLAN), Plan de desarrollo económico y social 1989-1994, San Salvador, MIPLAN, 1990, p. 11.

25. Ibid., pp. 11-12.

26. Ibid. 
El establecimiento de una economía social de mercado conlleva una redefinición y limitación del rol del Estado. Para cumplir con esta nueva concepción del Estado hay necesidad de una modemización institucional, incluyendo reformas administrativas, operacionales y jurídicas, y un esfuerzo para reorientar la inversión pública".

(ii) Priorización y evaluación. "Ante la escasez de recursos y otros limitantes existentes, es imposible realizar todas las acciones o satisfacer todas las necesidades simultáneamente. Esto lleva a la necesidad de priorizar, establecer secuencias de acciones y definir gradualidades. Al establecer las prioridades se dicta el nivel de importancia; y en el caso de la secuencia de acción a seguir, lograr un empleo eficiente de los recursos y coadyuvar a la eliminación de ineficiencias generadas por la duplicidad, y en algunos casos, multiplicidad de funciones por parte de las instituciones del Estado".

(iii) Descentralización. "El Estado salvadoreño se ha caracterizado por el concepto de que la autoridad central debe concentrar todo el poder y por ende, el poder radica en San Salvador. Para transformar al Estado en un ente dinámico, eficiente y que responda a una concepción democrática, debe descentralizar sus acciones, ya sea dentro de las instituciones que lo conforman o a través de una mayor participación de los gobiernos locales. Así se busca lograr una presión desde abajo, democráticamente, en la toma de decisiones por las autoridades de gobierno".

(iv) Participación. "Es necesario ampliar la participación de la sociedad civil con el Estado en toda aquella función que ayude a aliviar la carga del mismo y permitan una sana competencia. De esta forma se busca mejorar la eficiencia en el uso de los recursos públicos, facilitar la reactivación económica y estimular la acción solidaria del sector privado". (v) Privatización. "La privatización de aquellas actividades que competen al sector privado y que están en manos del Estado es un paso fundamental para mejorar, por un lado, la precaria situación fiscal y eliminar su acción interventora; y por otro, para sentar los criterios jurídicos de propiedad privada que actúan como elementos básicos para el desarrollo económico y social"27.

\section{B. Políticas sociales}

El marco englobante de las políticas sociales bajo la administración Cristiani es "elevar la calidad de vida de la población e iniciar un proceso sostenido para la erradicación de la extrema pobreza en El Salvador. Las condiciones de extrema pobreza que ya significaban un problema muy agudo en la década pasada, se han magnificado en los últimos años, a tal punto de afectar actualmente a más de un tercio de las familias salvadoreñas. Su gravedad exige que todos los esfuerzos de la sociedad salvadoreña se orienten prioritariamente hacia su superación"28. Los postulados sociales del programa de gobierno de Cristiani son los siguientes: (i) el Estado debe tener una participación fundamental en la erradicación de la pobreza extrema; (ii) la satisfacción de las necesidades mínimas sociales crea las condiciones necesarias para el logro de una efectiva igualdad de oportunidades; (iii) solamente con el logro del desarrollo social es factible conseguir paralelamente un crecimiento económico sostenido; y (iv) el progreso social resultante de mayores oportunidades de desarrollo integral conduce hacia la armonía y la paz $^{29}$.

Para dar concreción al propósito arriba señalado se plantean dos conjuntos de políticas sociales: políticas de compensación social y políticas sociales sectoriales ${ }^{30}$.

27. Ibid., pp. 16-18.

28. Ibíd., p. 49.

29. Ibíd., p. 49-52.

30. Estas políticas son expuestas entre las páginas 61 y 78 del Plan de desarrollo económico y social 1989-1994. 
Las políticas de compensación comprenden los siguientes aspectos: (i) construcción y reconstrucción de obras de Infraestructura Básica Municipal con la participación del sector privado; (ii) realización de Cabildos Abiertos con el objeto de que las comunidades expresen sus necesidades más sentidas; (iii) construcción y reconstrucción de obras de Infraestructura Básica Municipal con la participación del sector privado; (iv) proporcionar asistencia financiera a la población beneficiaria para la ejecución de pequeños proyectos productivos; (v) asistencia técnico-financiera a los Gobiemos Municipales; (vi) dotación de mobiliario, materiales y equipo a escuelas de nivel primario, unidades y puestos de salud; (vii) construcción de obras de infraestructura básica comunal con la participación del sector privado; (viii) creación y funcionamiento de Guarderías y capacitación de madres educadoras voluntarias; (ix) apoyo al funcionamiento de comedores populares; $(x)$ capacitación a promotores en salud preventiva y desarrollo de actividades de mejoramiento para la salud; (xi) proporcionar Asistencia Técnica y Crediticia a la población beneficiaria para la ejecución de pequeños proyectos productivos generadores de empleo e ingreso; (xii) desarrollar programas de capacitación para funcionarios municipales en aspectos administrativos, financiero-contable y de ejecución de proyectos; (xiii) apoyar actividades relativas a la organización comunal y formación de Comités Pro-Mejoramiento Comunal. (PROCOM); (xiv) organizar asociaciones de desarrollo comunal prioritariamente en áreas rurales; $(x v)$ proporcionar capacitación productiva y social a las comunidades; ( $x v i)$ brindar asistencia técnica, financiera y administrativa a las comunidades para la ejecución de pequeños proyectos generadores de empleo e ingreso; (xvii) efectuar actividades tendientes a elevar el nivel educativo, organizativo y técnico laboral de la población objetivo; ( $x$ viii) proporcionar asistencia técnica, financiera y administrativa a la población objetivo para la ejecución de proyectos productivos generadores de empleo e ingreso; ( $x i x)$ ejecutar proyectos de construcción y mejoramiento de vivienda; $(x x)$ llevar a cabo el reasentamiento de la población objetivo, utilizando criterios de desconcentración y aprovechamiento de tierras ociosas disponibles; (xoci) ejecutar proyectos de infraestructura básica con participación de los beneficiarios en los asentamientos; (xxii) reconstrucción y reparación de infraestructura educativa; (xxiii) reconstrucción y reparación de mercados de mayoreo; (xxiv) creación de líneas de crédito para

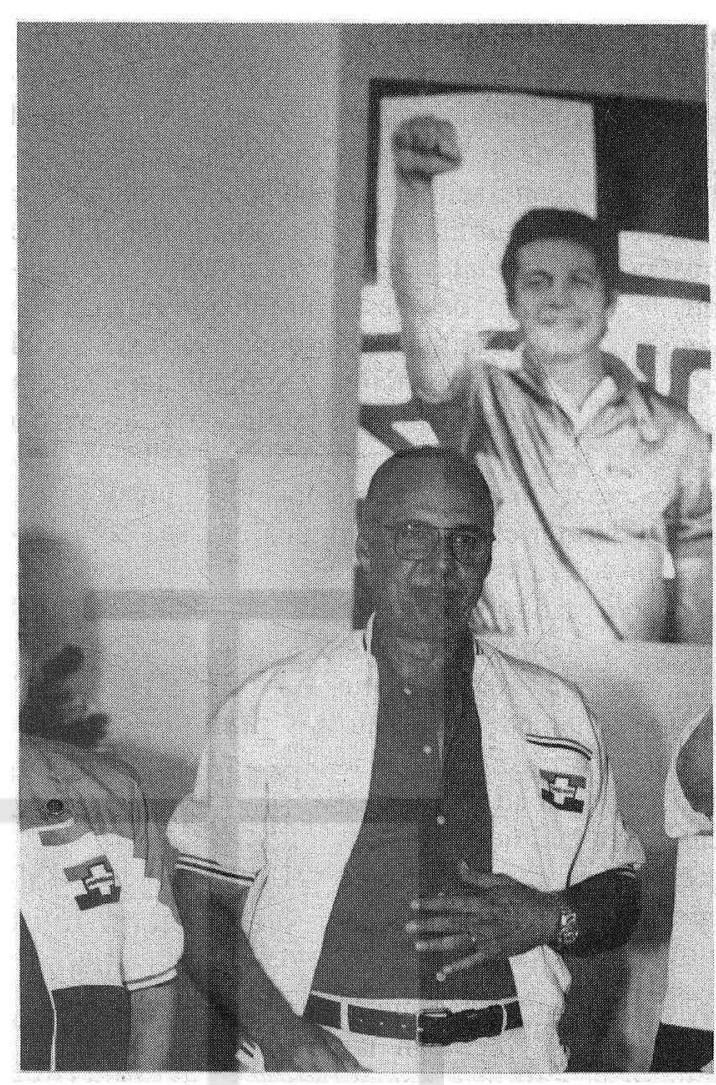

apoyar microempresas del sector informal; $(x x v)$ reconstrucción y reparación de la carretera San Salvador-Apopa, y (xxvi) estructuración del Fondo de Inversión Social.

Las politicas sociales sectoriales involucran los siguientes elementos: $(a)$ sector salud y nutrición, (b) sector educación, (c) sector vivienda, $(d)$ sector área integral de la familia, (e) sector previsión social, $(f)$ sector laboral y $(g)$ política ecológica.

\subsubsection{La administración Calderón Sol (1994- 1999)}

\section{A. Políticas económicas}

La preocupación económica fundamental de la administración Calderón Sol es "mantener un crecimiento enérgico y sostenido, mediante la modernización tecnológica, la continua capacitación de los trabajadores y la inserción del país a las cadenas de producción mundial. Este proceso tiene como finalidad generar más y mejores recursos, tan- 
to para retroalimentar el proceso económico y mejorar la infraestructura, como para financiar la inversión en la persona humana y ampliar la calidad y cobertura de los servicios sociales. Consecuentemente, la generación de recursos financieros se concibe como un medio para la materialización de una política social sólida y dinámica"31. Precisamente, el "Plan de Desarrollo Económico tiene como objetivo facilitar la inserción del país en el proceso de modernización y globalización, para entrar con decisión por el camino del desarrollo integral, sostenido y sustentable (...). Esto demanda la creación de mecanismos y de una institucionalidad en el área económica que sea compatible con los fundamentos de una sociedad libre, democrática y participativa, que sustente un sistema que brinde igualdad de oportunidades para competir, que permita equidad en el goce de los beneficios del progreso y ofrezca múltiples opciones para que haya movilidad social" ${ }^{12}$.

Para alcanzar las metas señaladas, se plantean las siguientes políticas económicas $^{33}$ :

(a) Política cambiaria. "De todos los sistemas cambiarios, el más potente para una sana gestión macroeconómica es el de libre convertibilidad con cien por ciento de respaldo, por la confianza, estabilidad y credibilidad que genera. Esto es más relevante si cualquier déficit fiscal temporal es financiado en forma sana y es compensado por superávit en otro período, de modo de asegurar un equilibrio promedio en el largo plazo. Además, el hecho que la inflación interna se sitúe a un nivel cercano a la mundial genera estabilidad y confianza. Sin embargo, también se debe reconocer que nadie puede garantizar que, atraídas por soluciones fáciles de corto plazo o por el populismo, las autoridades no realizarán modificaciones en el futuro, frente a grandes desequilibrios macroeconómicos".

(b) Política comercial. "La modemización del sector privado es indispensable para facilitar el proceso de inserción del país a las cadenas de producción mundial. En este sentido, el papel del gobiemo es fundamental para promover y garantizar un orden de libre competencia, con igualdad de oportunidades, a fin de que las fuerzas del mercado generen un aumento de la productividad. Por otra parte, es necesario reducir los costos de operación en el país, donde -además de las reformas del sector público- se suma la rebaja de los aranceles, que también contribuyen a reducir los costos y obtener mayores beneficios de la globalización... La reducción gradual de los aranceles y la eliminación de las prohibiciones y cuotas de importación contribuirán significativamente a la construcción de una economía totalmente libre. Esto será complementado con otras acciones en los otros campos de política económica y con mejores condiciones socio-jurídico-políticas, que den confianza a los inversionistas nacionales y extranjeros. Esto también resultará en un incremento del salario real, sin ningún efecto inflacionario porque los precios de los productos de consumo tenderán a bajar como reflejo de la eliminación de las rentas políticas que permite el actual sistema y la generación de una mayor competitividad y mejor calidad de productos y servicios en el mercado nacional".

(c) Política fiscal. "La política fiscal debe buscar equilibrios y en lo posible el superávit en las operaciones del sector público, a fin de asegurar

31. Gobierno de El Salvador, Plan de gobierno de la república de El Salvador 1994-1999, San Salvador, 1996, p. 6.

32. Ibíd., p. 15.

33. Estas políticas se exponen entre las páginas 30 y 70 del Plan de gobierno de la república de El Salvador 19941999. 
condiciones de estabilidad macroeconómica, de solvencia de la moneda y generar confianza en los inversionistas nacionales y extranjeros. Por otro lado, la política fiscal debe convertirse en una heramienta de orientación del desarrollo, mediante la asignación prioritaria de recursos públicos para la inversión en capital humano, en calles, carreteras y puentes, seguridad pública y desarrollo local. Se racionalizará el tamaño del sector público $\mathrm{y}$, como mínimo, se reducirá la burocracia redundante teniendo una visión humana, ya que detrás de cada trabajador hay una familia y necesidades que satisfacer".

(d) Modernización y apertura del sistema financiero. "Dado los objetivos de insertar a El Salvador en las cadenas de producción mundial y convertirlo en un centro de operaciones financieras internacionales es fundamental establecer condiciones equitativas para la operación de las instituciones financieras nacionales y extranjeras, a fin de hacer atractivo el país. En este contexto, será fundamental un cambio en el enfoque del sistema financiero, el cual deberá mejorar su eficiencia y eficacia operativa y de servicio, a fin de poder competir adecuadamente y constituir el centro promotor del desarrollo económico del país. También es necesario velar por la solvencia del sistema para que el público tenga un alto grado de seguridad en el manejo de sus recursos. Además, es trascendental fortalecer y desarrollar el mercado de valores en un ambiente de competencia bursátil, a fin de generar nuevos instrumentos para la captación de recursos necesarios para la inversión productiva, la expansión del comercio y poder mantener tasas de crecimiento económico altas y sostenibles."

(e) Modernización del sector público. "La reforma del sector público involucra un complejo proceso que toma muchos años en concretarse y se caracteriza por ser dinámico, lo que significa que está bajo constantes ajustes y donde una vez terminado el programa inicial, se abre un nuevo proceso de acuerdo con las nuevas demandas que tenga la sociedad. Los procesos de reforma del sector público son, generalmente, traumáticos y lentos, porque son realizados por personas dentro del mismo sector, que -en muchos casos- le temen al cambio, que ven peligrar sus niveles de poder, que sienten que se reducen sus campos de jurisdicción y que enfrentan variaciones en los requerimientos $y$ en las exigencias y formas de ejecutar sus traba-

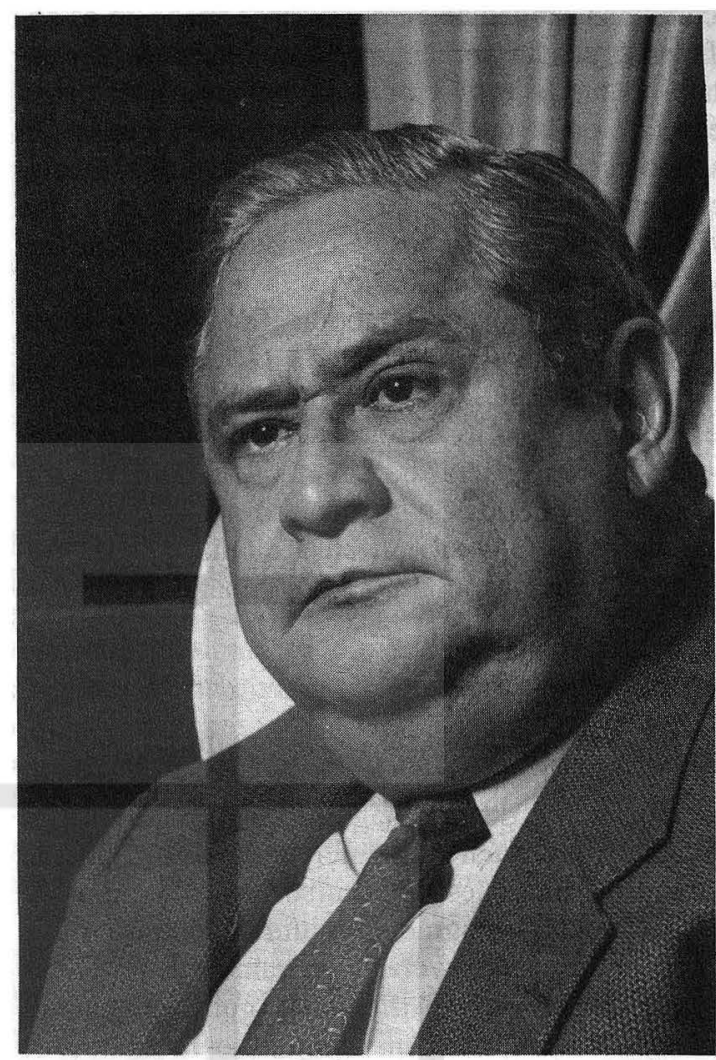

jos. Hay otros que estiman que pierden muchas de las prebendas que los mantienen en situaciones privilegiadas a costa de toda la sociedad, por lo que presentan una natural reticencia al cambio".

(f) Política de desarrollo local. "La estrategia del Plan Económico incluye la introducción del país al proceso de globalización. Similarmente, en una conjunción de la política económica con la social, se busca generar un proceso de apertura y globalización hacia el interior del país. Por medio de este proceso se desea estimular una desconcentración de las fuentes de producción y de trabajo hacia las localidades, en función de las ventajas que ofrezcan".

(g) Políticas sectoriales. "En un sistema de economía de mercado no se conciben políticas sectoriales, ya que la mejor política sectorial es una política macroeconómica que fija reglas claras y estables, da libertad a los agentes económicos, facilita la creación de recursos financieros para apoyar la inversión y genera estabilidad y confianza en el corto-mediano plazo. Si bien ésta es una 
condición fundamental, en muchos casos no es suficiente, por las condiciones a que puede haber estado expuesto un sector de la economía. Un caso especial es el del sector agrario que requiere un apoyo especial dada la magnitud de la transformación que debe enfrentar, la difícil situación que vive después de 12 años de conflicto, que paralizaron su progreso tecnológico y la gran cantidad de trabajadores que en él labora. También el sector turismo requiere una atención especial debido a que el país debe construir una imagen a nivel internacional. Para los otros sectores, sólo se presenta una visión general de las medidas de política o acciones requeridas para mejorar las condiciones en que se desenvuelven, en armonía con las demandas de una economía más competitiva".

\section{B. Políticas sociales}

El marco englobante de las políticas sociales bajo la administración Calderón Sol es la preocupación acerca de la "magnitud de los problemas sociales", los cuales requieren para su atención "grandes cantidades de recursos, muchos años de trabajo social integrado, voluntad, dedicación y paciencia para perseverar y un cambio tanto en las estructuras de las instituciones gubernamentales del área social como un cambio en la actitud de los privados, que deben contribuir más solidariamente e involucrarse en la lucha contra la pobreza, que es un imperativo de cristiana conciencia social y una condición necesaria para la paz social"34.

La situación nacional e internacional plantea retos importantes a los trabajadores y empresarios del país, los cuales "tienen una gran capacidad para enfrentar los desafíos de la globalización, capacitarse en un período breve y absorber nuevas tecnologías para competir en el mundo". De lo que se trata es de lograr lo siguiente $(a)$ "hacer de El Salvador, un país de propietarios, facilitando el acceso a la propiedad mediante una adecuada política macroeconómica y generando oportunidades para beneficiarse del crecimiento de la economía. Esta premisa tiene su fundamento en las características propias del ser humano, que aspira a poseer algo, a buscar una seguridad para el mañana. También tiene fundamentos en los sentimientos nacionalistas, que nacen de la satisfacción que la sociedad les brinda de ser parte del proceso económico, participar del progreso social y de poseer algo propio, que en su conjunto hacen la riqueza de toda la nación, la que todos desean proteger, preservar e incrementar, por su bien personal, el bien común y el de las futuras generaciones"; $(b)$ "lograr el mayor grado de participación posible de la población en la toma de decisiones, fortaleciendo aún más los gobiemos municipales y los cabildos abiertos, por medio de un proceso que promueva la descentralización de los servicios sociales que presta el Estado. Ésta es una condición fundamental para la total democratización de la sociedad salvadoreña, que incentiva la participación de las comunidades en la búsqueda de las soluciones a sus problemas y que genera condiciones para que ejerzan contraloría social sobre los servidores públicos y la calidad de los servicios que les proveen"; $(c)$ "consecuentemente con lo anterior, [persigue] introducir mecanismos que den vida y autonomía nacional a un nuevo concepto de desarrollo socio-económico local, a fín de que los beneficios del progreso económico y social lleguen a todo el territorio nacional. También se busca generar una base que fomente la inversión privada local, a fin de elevar los niveles y calidad de vida en todo el territorio, propiciando con ello un desarrollo armónico y equilibrado a nivel nacional"35.

En función de lo anterior se proponen una serie de medidas de política social, las cuales se insertan en dos grandes bloques - uno a corto plazo y otro a mediano-largo plazo- con sus respectivas áreas.

(A) Áreas y políticas de corto plazo: (a) reconstrucción nacional, $(b)$ infraestructura básica, (c) infraestructura económica básica y servicios de apoyo, $(d)$ fortalecimiento municipal y descentralización, $(e)$ familia y grupos vulnerables, $(f)$ agua potable y saneamiento ambiental, $(g)$ medio ambiente y desarrollo territorial, $(h)$ vivienda y desarrollo urbano, $(i)$ juventud y $(j)$ sector micro y pequeña empresa. (B) Áreas y políticas de mediano y largo plazo: (a) educación y cultura, $(b)$ salud y (c) vivienda.

34. Ibíd., p. 161.

35. Ibíd., pp. 164-165. 


\subsection{Los organismos financieros internacionales}

Las dos administraciones de ARENA han sido fuertemente influenciadas por las recomendaciones de organismos financieros intemacionales, tales como el Fondo Monetario Internacional (FMI), el Banco Mundial (BM) y el Banco Interamericano de Desarrollo (BID) ${ }^{36}$, los cuales han condicionado gran parte de su ayuda económica a la implementación de un serie de medidas económicas y sociales. Estas medidas casi automáticamente se han convertido en políticas de gobiemo, las cuales han sido incorporadas a los respectivos planes de desarrollo económico y social. Sin lugar a dudas es discutible la tesis de que todo lo que han hecho ambas administraciones en materia económica y social ha estado determinado por las directrices de los organismos financieros internacionales. Sin embargo, lo que no puede negarse es que esos organismos han tenido una presencia importante en el quehacer gubernamental, incidiendo decisivamente en áreas económicas y sociales claves para el país.

En su conjunto, en la última década, las recomendaciones de los organismos financieros internacionales a los gobiemos salvadoreños han apuntado a dos objetivos: liberar a las fuerzas del mercado del efecto perturbador del Estado y apoyar la inserción de la economía nacional en el proceso de globalización. Lo primero ha implicado la puesta en marcha de una serie de medidas orientadas a la reducción del Estado y a la privatización de determinados servicios públicos; lo segundo, a la implementación de medidas tendientes a favorecer el crecimiento económico y la apertura comercial. Además, para cada uno de esos grandes propósitos los organismos financieros internacionales han ofrecido asistencia financiera y asesoría técnica necesaria para asegurar el éxito de las medidas implementadas. Asimismo, a la par de esas metas, se han planteado exigencias complementarias en materia social, en vista de que las medidas de reforma económica traen consigo inevitables costos sociales que tienen que ser paliados. En resumen, las medidas económicas y sociales recomendadas y/o exigidas por los organismos financieros internacionales se han convertido en políticas de go- biemo. A continuación reseñaremos las recomendaciones económicas y sociales hechas por los organismos financieros internacionales y que han sido asumidas como políticas de gobierno por las dos administraciones de ARENA.

En materia económica, uno de los rubros que más ha ocupado la atención tanto del Fondo Monetario Internacional (FMI) como del Banco Mundial (BM) han sido los Programas de Ajuste Estructural, exigidos por esos organismos financieros a todos aquellos países con agudos desequilibrios económicos y con necesidades urgentes de recursos financieros. Esos programas tienen como propósito "mejorar el clima de las inversiones en un país y lograr estabilidad financiera por medio de políticas tales como reducciones en la reglamentación que gobierna el comercio y la inversión, el aumento de las divisas por medio de la promoción de exportaciones, y la reducción de los déficit a través de un menor gasto público. Comúnmente, los programas de ajuste estructural incluyen la devaluación de la moneda, la liberalización del comercio y los mercados, la disminución de los gastos sociales, la privatización de las empresas estatales, la supresión salarial, la eliminación de reglamentos que gobiernan al sector privado, restricciones al crédito, la elevación de tasas de interés, y un desplazamiento de la producción de alimentos para el mercado nacional hacia la producción para la exportación. Los programas de ajuste estructural forman parte de casi todas las transferencias de ayuda hacia los países del sur porque los gobiemos y los bancos privados exigen que el FMI avale todos los préstamos y créditos comerciales, medidas para aliviar la deuda, y la ayuda bilateral" ${ }^{37}$.

Como puede verse, los programas de ajuste estructural constituyen un paquete completo de medidas económicas, cuyo fin explícito es el desmantelamiento del Estado de bienestar y la liberalización comercial. El conjunto de medidas propuestas apuntan a esos propósitos, los cuales, una vez cumplidos, darán paso al crecimiento y la estabilidad económicas. Tal como se dice en un documento del Banco Mundial: "los programas de ajuste aprovechan los cambios en las políticas fiscal, monetaria y sectorial, y en los reglamentos e institu-

\footnotetext{
36. J.E. Ruthrauff, Una introducción al Banco Interamericano de Desarrollo, al Banco Mundial y al Fondo Monetario Internacional para principiantes, Washington, Centro para la Educación Democrática, 1994.

37. Ibid., p. 8.
} 
ciones para alterar los precios relativos y el nivel de gasto público $\mathrm{y}$, de esa manera, reorientar la actividad económica... Para el crecimiento y el desarrollo es esencial asegurarse de que por medio del ajuste se logre un cambio equilibrado en el gasto público y una reasignación sectorial apropiada de los recursos. El sistema financiero externo desempeña una función importante: moviliza el ahorro nacional y lo dirige hacia las inversiones rentables"38.

Desde la década de los años ochenta, en El Salvador, al igual que en el resto de países centroamericanos, se ha buscado implementar, con diferentes grados y ritmos, las medidas planteadas en los programas de ajuste estructural. En ese entonces, "los gobiemos y las élites centroamericanas concluyeron que existía una crisis económica intratable y empezaron a aplicar medidas prescritas en las cuales encontraron un alivio inmediato. Al aceptar los diagnósticos de las instituciones financieras internacionales... se les entregaron los fondos de estabilización, préstamos 'puente' y una renegociación de la deuda externa o reprogramación de sus pagos. Los componentes, individualmente diseñados, de los paquetes de estabilización, cuya entrega dependía del compromiso del país al curso de los Programas de Ajuste Estructural, establecieron la lógica de reestructuración en las políticas fiscales y monetarias ( $y$ de extensión sociales) del Estado respectivo"39. En los años noventa, esos programas continúan orientando buena parte del quehacer gubernamental de los países del área ${ }^{40}$. En .El Salvador han cobrado particular fuerza medidas como las siguientes: recortes presupuestarios en áreas sociales, privatización de empresas y servicios estatales, liberalización del comercio y repliegue del Estado de toda una gama de intervenciones en el mercado.
Como señala F. Judson, "es un cliché que el ajuste y la reestructuración tienen unos costos sociales y políticos, al punto que el Fondo Monetario Internacional, el Banco Mundial, la Agencia Internacional para el Desarrollo, sus respectivas oficiales y publicaciones lo repiten casi diariamente en los noventa"41. Pero estas instituciones no sólo hacen pública su preocupación por los costos sociales de los programas de ajuste estructural, sino que proponen a los gobiemos una serie de medidas de carácter social encaminadas a paliar sus efectos más graves. Uno de los primeros organismos financieros que asumieron las implicaciones sociales de los programas de ajuste fue el Banco Interamericano de Desarrollo, que en 1992 creó un Fondo Multilateral de Inversiones, con el objeto de apoyar la "modernización" económica y aliviar los costos humanos y sociales ocasionados por el proceso de ajuste estructural ${ }^{42}$.

Por su parte, el Banco Mundial, en su Informe sobre el desarrollo humano 1990 , propuso una serie de medidas sociales que, a partir de entonces, fueron incorporadas por diferentes gobiernos, incluidos los dos gobiernos de ARENA en El Salvador, como parte de sus programas de desarrollo social. Las medidas más importantes se orientan a las siguientes áreas: (a) reducción de la pobreza: "lograr un modelo de desarrollo capaz de reducir efectivamente la pobreza requiere políticas que proporcionen oportunidades a los pobres y les permitan participar en el crecimiento"43; (b) salud, educación y otros servicios sociales: "el progreso de los sectores sociales requiere un compromiso de largo plazo en cuanto a hacer que la educación, la atención de la salud y otros servicios sociales sean accesibles a todos los niveles de la sociedad.

38. Banco Mundial, Informe sobre el desarrollo mundial 1989, Washington, Banco Mundial, 1989, p. 12.

39. F. Judson, "El ajuste y las agendas nacionales centroamericanas", ECA, 597-598, julio-agosto, 1998, pp. $597-$ 598.

40. Ver Ibid., p. 598.

41. Ibid., p. 604.

42. Ruthrauff, J.E., Una introducción al Banco Interamericano de Desarrollo... p. 4.

43. Banco Mundial, Informe sobre el desarrollo humano, 1990, Washington, Banco Mundial, 1990, p. 83. 
Allí donde falta ese compromiso y donde las políticas públicas no han logrado llegar a los pobres, las necesidades sociales siguen siendo abrumadoras" ${ }^{4}$; (c) inversión en las personas: "es abrumadoramente evidente que el capital humano constituye uno de los elementos clave para reducir la pobreza. Además, las mejoras en la salud, la educación y la nutrición se refuerzan recíprocamente. Sin embargo, los pobres por lo general no tienen acceso a los servicios sociales básicos. Se invierte demasiado poco en su capital humano, lo cual aumenta la probabilidad de que ellos y sus hijos sigan siendo pobres. Para romper este círculo vicioso, los gobiernos deben hacer que el objetivo de que los servicios lleguen a los pobres sea una prioridad por derecho propio"45; (d) nutrición: "así como el nivel de educación de los padres tiene un efecto positivo en la nutrición de los hijos, una mejor nutrición acrecienta la capacidad del niño para aprender... Puesto que un mejor nivel de salud y nutrición ejerce un efecto positivo en la productividad, la inversión en esos rubros contribuye también a reducir la pobreza" ${ }^{\text {"at }}$; $(e)$ planificación familiar: "el tener demasiados hijos pone en peligro la salud de las madres y agrava los problemas de la pobreza... La prestación de servicios de planificación familiar es la forma más directa de reducir la fecundidad, aunque también ayudan a ello la disminución de la mortalidad infantil y en la niñez y la creación de mejores oportunidades de educación y trabajo para las mujeres"'47.

\section{La administración de Francisco Flores en perspectiva}

ARENA se hizo del poder ejecutivo por tercera vez consecutiva. Ello siembra dudas más que razonables acerca del futuro económico, social y político de El Salvador. Francisco Flores, a lo largo de su campaña política, en lo absoluto se comprometió a cambiar la orientación económica seguida por sus predecesores; nadie dice que no lo intentará ahora que ya tomó las riendas del ejecutivo, pero hasta el momento no ha dado señales de que uno de sus objetivos va a consistir en modificar el rumbo funda- mental del esquema económico neoliberal iniciado por la administración de Alfredo Cristiani (19891994) y continuado por la administración de Armando Calderón Sol (1994-1999). Tampoco está claro cómo, de intentarlo, va a hacer frente a los grupos de poder dentro del partido que seguramente querrán anteponer sus intereses particulares a los intereses del país en su conjunto. Así las cosas, lo que se anuncia en el horizonte en materia económica no es desconocido por los salvadoreños, pues ya se han tenido diez años de lo mismo.

En materia social, tampoco hay que hacerse mayores expectativas. Ciertamente, si el partido ARENA quiere trabajar desde ya en las condiciones que harían posible un mandato gubernamental más, la administración de Flores deberá hacer algo de lo que el gobiemo de Calderón Sol ofreció y no pudo (o no quiso) cumplir, como lo es incorporar la cuestión social al quehacer gubernamental ${ }^{48}$. Nadie dice que Flores no pueda prestar atención a la política social de una forma menos cosmética que la seguida por Calderón Sol, pero para ello el nuevo presidente tiene que hacer a un lado el triunfalismo que caracteriza a su partido y afrontar con realismo las posibilidades de éste para continuar indefinidamente en el ejercicio del poder gubernamental. Esto no es tan fácil, dada la complacencia de la que hacen alarde los jerarcas areneros ante su tercer triunfo presidencial consecutivo.

En materia política, tampoco hay indicios de que las cosas vayan a mejorar. El nuevo presidente ha dado señales inequívocas de su empatía con el estilo de comportamiento tradicional de los líderes de ARENA. Muchas actitudes suyas durante la campaña hicieron recordar actitudes no tan memorables de Calderón Sol: desprecio a los oponentes políticos, alardes de quien se sabe con poder, prepotencia manifiesta... Nada es más nocivo para el desarrollo de una cultura política democrática como el que, desde la presidencia de la república, se promuevan actitudes autoritarias. Por otra parte, no es presumible que los partidos políticos y las figuras que los controlan vayan a asimilar la lec-

44. Ibíd., p. 84.

45. Ibíd., p. 90.

46. Ibid., p. 92.

47. Ibid., p. 93.

48. Ver "ARENA: la difícil conciliación entre lo económico y lo social", El Salvador Proceso, 856, 26 de mayo de 1999, pp. 2-3. 


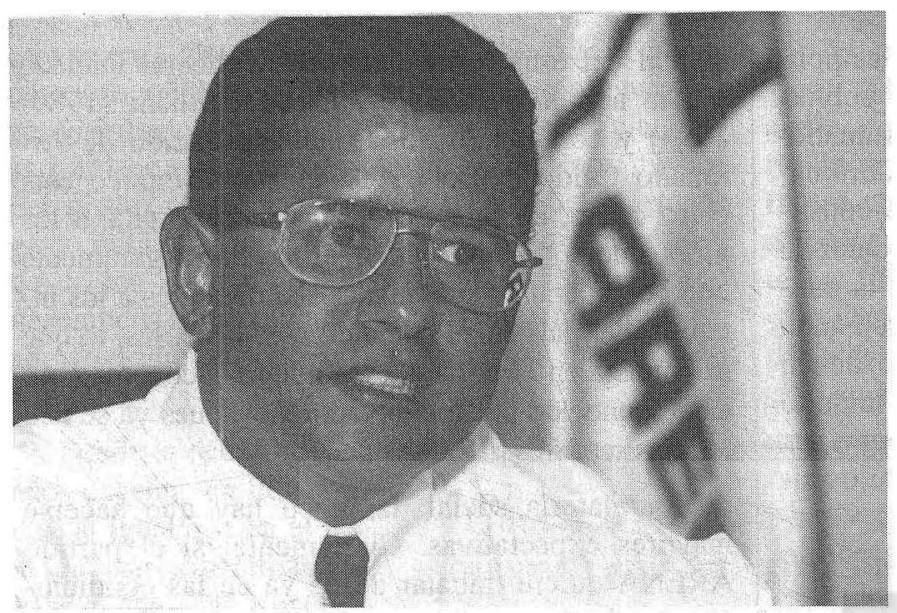

do por la borda la oportunidad para mantenerse, por un tiempo relativamente indefinido, gestionando los destinos del país. No es descabellado pensar, en este sentido, que el desafío de Flores es reconducir institucionalmente al partido para que éste se asegure un futuro político exitoso, por lo menos durante los siguientes diez o quince años. No es una tarea fácil la que tiene ante sí; incluso es probable que no pueda asumir todas sus consecuencias ${ }^{49}$.

Con todo, existe la posibilidad de que Francisco Flores salga adelante con su iniciativa y que la redefinición institucional de ARENA se haga realidad. En este caso, las aspiraciones del FMLN,

ción que se desprende, por un lado, de la victoria de ARENA; y, por otro, de la no participación en las votaciones de un 60 por ciento de los electores. Ambas cosas no son nuevas; sin embargo, los políticos nunca hicieron nada en el pasado para corregir sus vicios y limitaciones, por lo cual no es presumible que ahora vayan a hacer algo distinto a lo que están habituados a hacer.

De todos modos cabe la posibilidad de que Francisco Flores se muestre dispuesto a iniciar un proceso de cambio en las relaciones entre el Partido ARENA, el Estado y los grandes empresarios. Las señales que el presidente electo ha dado apuntan en esa dirección. Ciertamente, ante la resistencia que seguramente opondrán quienes promueven el maridaje partido-Estado-empresarios, cabe la posibilidad de que ese proceso se aborte o se quede a medio camino. De suceder esto, el fracaso no sólo sería de Flores, sino también de ARENA, que estaría echanprincipal partido de oposición, para relevar a ARENA en el ejercicio del poder ejecutivo se encontrarían en dificultades serias, amén del influjo que pudiera tener el fortalecimiento de este último partido en la configuración del poder legislativo. En otras palabras, la redefinición de ARENA, de tener éxito, puede reducir hasta límites insospechados las posibilidades políticas del FMLN. El probable giro institucional de ARENA, pues, plantea desde ya un grave desafío al FMLN: convertirse en un partido capaz de abanderar un proyecto nacional, fundamentado en la equidad social y la participación ciudadana. Si el Frente no logra asumir este desafío y ARENA consigue elaborar una fórmula social, política y económica que, aunque subordinados, incorpore la equidad social y la participación, las perspectivas del FMLN son en verdad sombrías ${ }^{50}$.

San Salvador, 15 de junio de 1999.

49. Ver "Perspectivas del nuevo gobiemo", El Salvador Proceso, 858, 9 de junio de 1999, pp. 2-3.

50. Ver "Perspectivas del FMLN", El Salvador Proceso, 854, 12 de mayo de 1999, pp. 2-3. 